\title{
A IMAGEM DE SI E DO OUTRO, ENTRE A IDENTIDADE E A GLOBALIZAÇÃO1
}

\author{
Ana Luiza Carvalho da Rocha
}

"Tratar-se-á de descontruir a noção de identidade, recusando-lhe o mito de uma insularidade" (Claude Lévi-Strauss, L’Identité)

Gostaria de introduzir o tema da Identidade, no início de minha apresentação, diretamente no interior do debate da Globalização uma vez que considero que este fenômeno remete, hoje, em suas múltiplas feições, ao tema, já clássico nas ciências humanas, da crise da civilização. Ou seja, no corpo de parte da problemática proposta por esta Oficina (Psicanálise e campos de cultura: identidades e diferenças, o tema da Identidade contempla as diferentes formas adotadas pelo mundo ocidental para pensar a própria imagem que as nossas sociedades complexas, moderno-contemporâneas, veiculam de si mesmas.

Alguns estudos recentes sobre globalização tem, inúmeras vezes, insistido sobre o problema da interpretação/tradução das culturas pela cultura de consumo como elemento chave para a compreensão tanto das raízes e conseqüências que o processo globalizador provoca no curso dos parâmetros da condição humana atual. quanto para os resíduos de sentido que escapa a sua tendência de promover a unificação do globo.

Em muitos destes estudos, a "globalização" desponta como um destino irremediável das culturas, um processo irreversível e violento, indicando, como causas e consequiências sociais deste fenômeno, a presença da incomunicabilidade da experiência do outro (individual ou coletivo) no interior de um processo globalizador, ao mesmo tempo, que informando a unidade de efeitos que provoca sobre as economias, políticas, estruturas sociais e percepções de tempo e espaço locais.

No entanto, para os antropólogos que atuam, nos dias de hoje, no interior das sociedades moderno-contemporâneas, o fenômeno indesejado e cruel da globalização adquire outros

\footnotetext{
1 Palestra proferida no XXIII Congresso Latino-americano de Psicanálise, Psicanálise e Campos de cultura.
} 
contornos, bem mais complexos. Pesquisando processos de fixação no tempo e no espaço dos grupos humanos, à revelia do processo globalizador, nós antropólogos reavaliamos o emprego do próprio conceito de Identidade que, num mundo pós-colonial, não pode ser pensado senão no corpo de conteúdos culturais profundamente heterogêneos. Ao mesmo tempo, damo-nos conta da vizinhança de processos de localização e dos processos de globalização que o impõem, ao antropólogo, o desafio de pensar o conjuntos das sociedades humanas para além de sua dispersão no tempo e no espaço.

Portanto, o debate em torno da controvérsia da condição contemporânea de nossa civilização - dedicada a explorar, ao mesmo tempo, o movimento de construção/consolidação de identidades e os processos de globalização - merece destaque, principalmente no âmbito de XXIII Congresso Latino-americano de Psicanálise, com referência ao VI Simpósio Internacional de Mitos como nos mostra o folder de divulgação do evento. Uma das razões para isso é que a tendência a exclusão e a fragmentação, no interior do fenômeno da globalização, percorre o nosso tempo, criando diferenças de sexos, diferenças étnicas, diferenças culturais, diferenças regionais, diferenças nacionais. Num mundo saturado de hibridismo culturais, o tema da Diferença sinaliza para o debate em torno da autênticidade, do Idêntico e do Mesmo (e das suas propriedades), no plano dos conteúdos culturais, isto é, do que lhes é próprio.

Em meio a luta em prol do respeito a Diferença e, em plena era da globalização, nunca é demais se retomar ao tema da Identidade, objeto já clássico de um seminário organizado, nos anos 70, por Lévi-Strauss e Jean-Marie Benoist, lembrando, segundo Zygmunt Bauman, a aungustiante dramaticidade de se viver, hoje, a ambivalência; a polaridade entre ordem e caos.

Num mundo pós-colonial, 20 anos após ter se realizado o Seminário conduzido por LéviStrauss, a Identidade continua a ser um tema atual, cada vez mais pensada como uma realidade efêmera, não substancial, cuja função é instável, ainda que tal fenômeno se configure no centro de processos globalizadores, uma vez que no centro de sua polêmica dramatizam-se trocas e conflitos de todas as ordens. Num mundo "implacavelmente ambíguo", o conceito de Identidade ainda revela sua força pois através dele podemos pensar tanto o enraizamento/localismo da Diferença, quanto seu oposto complementar, um outro movimento distinto do primeiro, a Unidade.

Entretanto, ao contrário de se tentar a reconciliação do conceito de Identidade com a ambivalência do mundo pós-colonial, temos insistido em operar com a dispersão da própria figura da Humanidade quando nos debruçamos sobre o fenômeno da globalização. A interpretação dos efeitos de processos globalizadores deixa a desejar quando os compreendemos no seu interior a noção de Identidade pela via exclusiva do mito da insularidade. 
Desta forma, no mundo contemporâneo, conferir às práticas sociais e aos conteúdos culturais, determinados sistemas de classificação e nomeação com base no mito da Identidade como insularidade é não perceber, no interior deste fenômeno, regularidades ou causalidades universais que impõem, aos cientistas sociais, a explicitação de seus julgamentos ético-morais (sobre o qual falarei mais tarde). Valendo-me aqui das sábias palavras de Lévi-Strauss, penso que o próprio conceito de Identidade constitui-se numa unidade globalizante.

Neste ponto, o conceito de Identidade como o conceito de Globalização aproximam-se em suas formulações. Ambos operam entre o polo da diversidade das culturas e o da singularidade histórica que as constitui. Isto é, ambos os conceitos postulam, ao mesmo tempo, uma natureza humana idêntica (todos construímos identidade, portanto, podemos afirmar que o fenômeno da globalização obedece às mesmas leis) e seus universais substancialistas ( toda a identidade está referida ao local, logo, o fenômeno da globalização aponta para um espaço-tempo singular tanto quanto para um sistemas de valores particulares que fundam os limites de seu território).

Excetuando-se as noções grosseiras de Identidade e de Globalização, dadas na imediatez de sua perfomatização banal (uma identidade "de superfície", nos termos lévi-straussianos), o que se coloca para o antropólogo é a exigência deste operar com ambas as noções, seguindo as suas múltiplas determinações, justamente onde a questão do Outro aparece como constitutiva da própria gênese do conceito de Identidade e, por conseguinte, de Globalização.

Deixando o tema da Globalização para mais adiante, gostaria de deter-me, com mais vagar, na noção de Identidade e suas múltiplas determinações.

O debate, sempre em voga, a respeito da propriedade de uma Identidade (individual ou coletiva) mobiliza tanto o tema do impróprio quanto do próprio, isto porque a noção de Identidade não dispensa a própria labilidade da configuração do corpo social, fenômeno sempre desfeito e eternamente reconstruído, à revelia do que antes afirmara a sociologia durkheimiana.

Isto torna-se ainda mais claro, na Antropologia, quando se observa o diálogo cultural que orienta a prática etnográfica e a sua feição relacional,. É no momento do encontro etnográfico, principalmente, quando tal diálogo deixa-se guiar pela dialética da diferença que preside as interações do etnólogo com o seu grupo pesquisado e que o tema do próprio e do impróprio adquire espessura de entidade epistemológica.

Em Antropologia, anular ou nuançar o ponto cego da Diferença, no interior da conformação da Identidade do próprio do etnógrafo, significa o perigo deste incorrer num 
“etnocentrismo por anexação", em termos lévi-straussianos. Por outro lado, para o antropólogo, superar este ponto cego significa recusar a sua identificação do que lhe é próprio, rumo a aceitação da discontinuidade de seu si-mesmo, advindo disto um sentimento agudo de desordem interior. Tal ação de descentração (nos termos piagetianos) cria a figura atópico do antropólogo, figura que é central para que ele reconheça que o tema da Diferença se instala no próprio seio da Identidade (o Outro constituinte do Mesmo). Segundo os termos de P. Ricoeur, o que só pode ser possível se o antropólogo experiencia o desarranjo entre as identidade-idem e a identidade-ipse.

Para o momento, já é suficiente que se possa reter, aqui, a premissa, tanto lógica quanto dramática, de que a afirmação do Mesmo, do Idêntico, da Identidade (do antropólogo, do "nativo", da figura da Humanidade, etc.) instaura-se no corpo da discontinuidade irredutível do simesmo, momento em que o Outro (Diferente/Estranho de mim mesmo) aparece como condição de possibilidade de afirmação de suas propriedades.

Tal comentário torna oportuno a lembrança de uma das aporias de Sto Agostinho sobre as intenções e distensões da alma humana, para exemplificar o que acabo de dizer: momento. Refiro-me aqui a passagem em que filósofo conduz uma reflexão sobre a interioridade do tempo a partir das propriedades do seu si-mesmo: Ele diz: "Eu conheço o Bem que eu quero, mas eu faço o Mal que eu não quero"-

A intenção é conduzir minha argumentação no sentido de provocar, aqui, a entrada da Imagem no corpo das reflexões feitas, até o momento, a respeito da condição ambígua que o fenômeno da Identidade encobre.

Valendo-me de Sto Agostinho, mestre da filosofia cristã, gostaria de apontar para a "simbólica do mal" (termos ricouerianos) que promove a afirmação da discontinuidade irredutível do logos na compreensão do si-mesmo no Ocidente. Propositadamente, ressalto aqui a tradição da cultura bíblica que orienta, muitas vezes, nossas indagações científicas e laicas sobre o tema da Identidade e nossas afirmações sobre a condição humana na civilização contemporânea.

Impossível não reconhecer que a aporia agostiniana aqui transposta insinua o desconforto que a presença da Alteridade/Diversidade no interior do Idêntico. A idéia da alteridade (que poderia ser aqui também insinuada no papel que desempenha a figura do Diabo na cultura bíblica) desperta ,na consciência do homem da civilização, a idéia monstruosa da errância do ser. A fantasmagoria da Alteridade no seio da Unidade que tanto inspirou algumas reflexões de 
Descartes em suas Meditações. Nos termos que insinua a aporia agostiniana, a presença do impróprio na configuração do próprio, ela remete ao "conceito de pecado original, de uma falta anterior a qualquer falta pessoal", ao mesmo tempo que denuncia uma vontade, no interior do ser, que escapa a si mesmo, e que pode obedecer a outra lei que não ela mesma.

Numa arqueologia dos próprios saberes científicos, posso reconhecer aí também presença da controvérsia Identidade e Imagem. Para tanto valho-me, agora, dos comentários do profeta Jeremias, no Velho Testamento, para transpor o tema da Identidade, relacionando-a ao tema Imagem. Retiro aqui, parte de seus comentários, em particular, ao momento em que este profeta, comparando o negrume da pele do etíope, atribui-lhe as razões internas de sua má inclinação: "Pode um etíope mudar a sua pele, um leopardo as suas pintas? Podeis vós, também fazer o bem? Vós que estais acostumados ao mal?"

Pode-se ver aí, na gênese do mito da Diferença do qual é portador o Ocidente judeucristão, a dialética indissociável do dentro/fora que desafia tanto desafia o logos do homem da civilização. Os comentários do profeta atingem a dimensão de um luta para impor ao próprio uma representação. A indeterminação do próprio (o bem) exige sua redução a uma representação absoluta, uma modelagem, a do si-mesmo do profeta e a do seu monoteísmo. O acidente do bem, envolto na alteridade da pele negra do etíope, traz, à consciência do profeta, a ambigüidade que preside a afirmação de um valor e o julgamento de uma atribuição de propriedade. Isto nos faz pensar em que medida, na tradição de pensamento ocidental, a visibilidade e a lisibilidade do mundo e do ser aparecem como fenômenos solidários da figura identitária de homem que encerram.

Portanto, mesmo no plano do Idêntico, a Imagem, na cultura bílica, torna-se fonte de ambigüidade pois desempenha o papel de transito entre o crer (aspecto esotérico da Idéia) e o saber (aspecto exotérico da Idéia) e a meio caminho entre a construção da unidade do ser e a sua desconstrução face a pluralidade desesperante do mundo.

A razão que conduz minha argumentação para esta direção é simples. Refletir com mais acuidade sobre as repercussões que advém a presença da Alteridade/Diferença no âmago do próprio ser, tal qual ela se manifesta na figura do homem da civilização gerada no Ocidente. A afirmação da Mesmo, do Idêntico face a Diferença, aparece, aqui, como condição do próprio homem da civilização pensar a sua negatividade, ou seja, viver autrement, a experiência da morte de si. 
Lembrando-me dos pensamentos bachelardianos sobre a dialética da duração, todo o julgamento de aparência positiva acerca da existência se processa no interior de um julgamento negativo, onde o que se desvenda é a inquietude humana diante da matéria perecível do próprio tempo.

Desta forma, considerando-se as formas, mais ou menos fiel, com que a imagem adequase a coisa representada - no caso da figura do homem ou da própria Humanidade - a Imagem, na consciência histórica do Ocidente, adquire múltiplas espessuras de abordagens.

Delas derivam-se muitas de nossas explicações semiológicas que assimilam a visibilidade da Imagem à um longa cadeia de fatos de explicações positivas que se encerram em si mesmos, ou mesmo a perspectiva hermenêutica que enfrenta o tema do simbolo, pensamento-imagem sempre indireto, como chave de acesso a lisibilidade do mundo das coisas, onde a coisa representada não se fecha sobre si mesmo.

\section{A Imagem}

"Todo o ser singular da consciência recebe suas determinações na medida em que o todo da consciência se coloca e é representado sob uma forma, não importa qual seja, o que nós denominamos de dado e da presença do conteúdo"

(Cassirer, La Philosophie des formes symboliques )

No plano da Identidade, quando se torna necessário precisar os seus vínculos com a imagem, poder-se-ia pensá-la da seguinte forma: a identidade só pode ser dada à consciência pela sua representação, seja a imagem traduzida como unidade subjetiva da consciência, seja como unidade objetiva do ser.

A imagem é, assim, presidida por uma função intelectual, porque simbólica, participando tanto da constituição do conceito de eu (por exemplo, da figura do homem da civilização, lugar onde se poderia pensar os processos de globalização) quanto do conceito de mundo, professado pelo Ocidente judeu-cristão.

Nesta medida, a característica singular dos vínculos que unem os temas da Identidade e a Imagem, sempre torna-se fonte de inúmeros problemas tanto mais complexos quanto mais as 
formas de se abordar o mundo das imagens encontram-se compromissada com o processo de desvalorização que sofre a Imaginação no interior do Ocidente.

Numa desvalorização da Imagem, negando-lhe um estatuto de inteligibilidade segundo a via de uma pensamento sensível, decorre disto a idéia do tratamento do tema da Identidade segundo um pensamento científico destituído de imagens. Vejamos como isto tem se aplicado no caso do tema da identidade nacional, no caso do Brasil, em particular, no caso dos traços identitários do ser brasileiro se ancorarem na figura do homem cordial.

Por um lado, os estados do ser brasileiro podem ser percebidos como propriedades do próprio ser, e neste caso, a presença da imagem da cordialidade nos rituais de trocas sociais com o estrangeiro, durante o carnaval, no Brasil podem, por exemplo, tornam-se propriedades do ser brasileiro. Por outro lado, pode ocorrer ainda que a unidade da imagem da cordialidade, objetivamente formulada pelo cogito do antropólogo, não seja percebida como parte de um pensamento sobre ele mesmo, o antropólogo, perdendo-se aí tensão entre a matéria do seu pensamento e a sua própria forma conceitual, o que faz com que a imagem da cordialidade seja tomada como uma formulação intelectual autônoma, independente da mise en scène do conteúdo que tenta apreender. Neste ponto, a imagem da cordialidade pretende-se independente das qualidade atribuídas ao mundo real pelas formas do pensamento.

Quanto aos vínculos entre Identidade e Imagem pode-se dizer, portanto, sem medo de errar que uma unidade de denominação implica uma unidade de significação. Há, portanto, uma interdependência entre elas. Em especial, a imagem tem o poder de representar o todo do ser, ao mesmo tempo que o reproduz na sua exterioridade. É na pregnância simbólica da Imagem que reside todo o problema da significação, da representação e da construção da consciência de si, do Idêntico ou do Mesmo, uma vez que o simbolismo que encerra a Imagem diz respeito a consciência humana, na mesma medida em que ela colabora com a imediata organização do real. Neste ponto, sem dúvida, trata-se de ressaltar que a Imagem enquanto conteúdo psicocultural da consciência é, ela mesma, objeto da consciência humana. Assim, a Imagem se constitui, nos termos kantianos, na própria “organização instauradora da 'realidade', sendo daí que a Imagem, no que tange a ambigüidade da Identidade, retira seu poder. A Imagem revela para a consciência humana que o mundo da propriedades das coisas não lhe é jamais presentado, mas representado através da construção de um sentido. 
A imagem portanto, não se reduz, como o deseja a hegemonia do Cogito, a unificação filosófica da pessoa, nem se encontra privada do principio unificador do sentido, como o deseja o pensamento agnóstico cientificista. A imagem não obedece, nem tampouco, as forças afetivas ou modelos sociológicos. A Imagem, no plano da configuração da descontinuidade formal da Identidade, só adquire coerência na percepção, na concepção, no julgamento e no raciocínio por meio do sentido que as impregnam.

O simbolismo, do qual é portador a Imagem, a liberta da causalidade material que constitui a Identidade imediata, projetando-a, nos dilemas do próprio e do impróprio, no corpo dos mitos cosmológicos do ser. Por exemplo, os mitos gerados no interior dos postulados do individualismo moderno e proclamados pelo pensamento cientificista do Ocidente. Ou seja, a obsessão do pensamento ocidental a respeito das propriedades, do próprio, no mundo das coisas e dos objetos, enlaça-se aos dilemas da unidade do ser, o que só pode ser atingido na origem do próprio movimento do ser em direção a continuidade/permanência do seu si-mesmo.

Desta forma, quando atribuímos a Imagem, em nossa obsessão desmedida pelo próprio, o poder do despertar a consciência do ser, ela participa dos dilemas da construção da pessoa cristã no mundo Ocidental. Ao contrário, se reconhecemos na Imagem seu poder de restituir a unidade simbólica ao ser, que não é simples redução do outro ao mesmo, resgatamos a unidade da criação que engendra a configuração do Mesmo, do Idêntico e os esforços de unificação que ele(s) contemplam.

Neste sentido, poder-se-ia dizer, valendo-nos dos comentários de Lévi-Strauss, que “somos prisioneiros de um mundo de 'imagens', mas não se trata de imagens que reproduzem o mundo das coisas. Trata-se de um mundo de imagens cujo princípio e origem tem por base a criação autônoma do próprio espírito."

Portanto, se a imagem constrói para nós o que chamamos de mundo real, por sua vez, ela esculpe as pedras das quais nos servimos para esculpir/modelar tanto o conceito de eu quanto o conceito do mundo. Neste sentido, o ser que o próprio da Imagem reivindica não se apresenta mais como simples dado, um vez que é na sua exteriorização que é dado, ao ser, conhecer-se. Neste sentido a imagem se apresenta sob a forma de um acontecimento espaço-temporal, criada e recriada na interdependência do fluxo perpétuo da construção do ser (indivíduo, sociedade, comunidade, grupo) 


\section{Globalização}

"O sentido da imagem do homem (que é um símbolo e esta ligado a um "vivido") não se recupera com a pretensão de sua dissecação não vivida dos conceitos, de definições claras, de longas cadeias da razão"

(G. Durand, Science de 1’homme et Tradition)

Sem dúvida, o simbolismo da imagem perde seu "direito a cidade" no Cogito cartesiano ao estabelecer o "reinado" do algoritmo matemático. O cartesianismo significou, de inúmeras formas, o triunfo do "signo" sobre o "símbolo". A imaginação e a sensação, desde então, tem sido rejeitadas como fonte de erro. A formulação "Eu penso, logo existo" tornou-se, genericamente, o último e único "símbolo" do ser- o Cogito.

$\mathrm{Na}$ linha de minha argumentação, poderia afirmar que o iconoclasmo radical do Ocidente tem ocasionado repercussões para o caso do tratamento conceitual da imagem: seu papel foi minimizado num universo onde triunfa a potência pragmática do signo. Eliminada a função simbólica da Imagem, ela torna-se ornamentalismo acadêmico ou pura "diversão", reduzindo-se o papel do ícone ao de decoração.

Distanciamo-nos progressivamente da tradicional filosofia da "cifra", que implicava a recondução dos mundo dos objetos sensíveis ao mundo das idéias, e deste ao mundo das "reminiscências". Nestes tempos remotos, longe de ser vulgar memória, a Imagem traduzia a imaginação como epifania. Recusado o platonismo, em prol de um pensamento direto, o Ocidente cultuou um tipo determinado de conceitualismo aristotélico cada vez mais carregado de empirismo.

Nada mais banal, portanto, se discutir os processos de globalização descarnados dos dados sensíveis presentes à Imagem uma vez que a unidade/discontinuidade do ser não é mais um mistério a ser desvendado ou interpretado. Nos termos durandianos, "o dogmatismo da letra, empirismo do pensamento direto e o cientificismo semiológico reforçam-se no curso da história do Ocidente iconoclasta". Em meio a recusa da Imagem como abertura espiritual para uma sensibilidade, o Ocidente iconoclasta, torna-se uma civilização que se afoga nas imagens, inventando a fotografia, o cinema e outros tantos meios numerosos de reprodução iconográfica. 
No entanto, Leibnitz, já há algum tempo, nos alertava para o fato da lógica das coisas, isto é, dos conteúdos conceituais fundamentais e das relações sobre os quais repousa a elaboração de uma ciência, não ser separada da lógica dos signos. Pensar, portanto, o caso da globalização nestes termos, tem aqui sérias implicações.

A nomeação dos processos de globalização, na era das novas tecnologias eletrônicas e digitais, caminha lado a lado com sua fixação numa imagem, a da própria sociedade contemporânea e os conteúdos culturais que ela veicula. Só isto já remete o tema da globalização aos outros dois anteriores, a Identidade e a Imagem, recém comentados.

Neste caso, o próprio conceito de globalização que empregamos hoje, aqui, já traz encoberto o "sentido" próprio de suas formas na consciência do homem contemporâneo, o que significa, para nós, antropólogos, que os processos de globalização só podem ser conhecidos pelo e no conjunto dos signos sensíveis que a sociedade contemporânea tem se utilizado para se exprimir.

Ressalto aqui, as inúmeras formas através das quais, o conceito de globalização se afirma tendo por base a sua negação: isto é, o reconhecimento da existência de entidades locais.

Ultrapassando-se, portanto, a observação da dimensão imediata do fenômeno da globalização (a homogeinização), pode-se ver que este conceito não pode prescindir, para ser compreendido, do fenômeno de separação entre fronteiras, de dois ou mais mundos, no interior do qual ele se expressa. Tal qual o tema da Identidade e da Alteridade aos quais me referi no início de minha apresentação.

Nestes termos, não seria de ser admirar que em meio aos processos de globalização possa se registrar o surgimento dos reginalismos, nacionalismos, fundamentalismos e localismos de todas as cores.

Torna-se necessário se delimitar, portanto, com mais rigor, em nossas análises do fenômeno contemporâneo da globalização, o que, de nossas análises, é simples "reação" ao mass media daquelas que se configuram como parte de sua "ação" sobre o próprio pensamento antropológico.

Em particular, quanto ao tratamento da imagem em documentários etnográficos, campo no qual me situo, em plena "era da globalização", tenho observado que nos valemos, muitas vezes, da Imagem sem relacioná-la à formulação de julgamentos e de juízos que presidem as "impressões" que vivenciamos no encontro com o Diferente, o 
Exótico, o Estranho.

\section{A imagem de si e do outro nos documentários}

Em Congressos internacionais e nacionais, por exemplo, tenho assistido a vídeos e filmes etnográficos cuja característica tem sido de perpetuar uma certa "imediatez" das qualidades ditas sensíveis de tais culturas.

Isto, no geral, por duas vias. Por um lado, presa de uma abordagem com base num sensualismo dogmático, os efeitos sensíveis da "globalização" sobre os conteúdos culturais são superestimados em detrimento da fecundidade dos fatores puramente intelectuais que geram. Por outro, numa perspectiva crítica, a imagem é aprisionada apenas em sua atividade de "mise.en forme" dos conteúdos culturais, ou seja, de modelagem de figuras criadas pelos antropólogos que produzem a validade objetiva de seus dados.

Em geral, documentários etnográficos tem repetido uma velha formula, já bastante desgastada, de tratamento da Imagem como unidade logicamente determinada por uma forma, vendo-se, na modalidade documental, o núcleo da própria objetividade da ciência antropológica, no geral, descartando-se o processo de interpretação/tradução que o gera.

A Imagem, assim apresentada (seqüências, planos, enquadramentos, ângulos), é associada a identidade dos conteúdos da consciência do etnógrafo documentarista, de uma consciência que só se verifica no que ela faz, não no que não é ou não possui.

Como parte da função simbólica da consciência do próprio antropólogo, as imagens, tal qual elas se expressam ao nível dos documentários que venho assistindo, inclusive, nos mass media, em canais fechados (à cabo), permanecem idênticas a elas mesmas, revelando apenas parte inexpressiva dos fluxos da consciência dos próprios grupos retratados em situação dialógica com os fluxos da consciência do próprio etnógrafo.

$\mathrm{O}$ documentarista tende a esquecer que as imagens apresentadas, no corpo de uma história/intriga/enredo, só podem se fazer presente à sensibilidade do espectador pela re-presentação da algo que é ausente à sua consciência. No sentido amplo do termo.(pelo reconhecimento da Imagem como recondução do sensível, do figurado ao significado, que, por sua própria natureza, é inacessível em termos conceituais. 
Embora trabalhando com documentário etnográfico, temo aqui em afirmar que o simbolismo das imagens que compõe as histórias por mim narradas, geram um modo de conhecimento jamais adequado, jamais "objetivo". Um documentário etnográfico torna-se, assim, portador de um conhecimento que se quer essencial mas não se basta a si próprio e trazendo nele, escandalosamente, a mensagens jamais explicitas (sempre ambíguas e freqüentemente redundantes).

No entanto, no plano dos fluxos da consciência, as imagens de nossos documentários, no interior de uma narrativa etnográfica que contemple o diálogo antropólogo/nativo, supõem diferentes etapas de "reflexão" por parte de ambos. Isto se, no interior do documentário, contemplamos o próprio processo de transformação dos conteúdos dos dados sensíveis registrados em campo em história a ser narrada. Isto é, se explicitamos, na construção do roteiro do documentário, que o mundo das imagens apresentadas se configura no interior da dramática intrínseca da descoberta da Diferença que o Idêntico encerra.

A situação trágica dos documentários etnográficos que produzimos, principalmente quando são veiculados/exibidos nos mass media, é que eles podem vir a cumprir o protocolo da era da globalização, ou seja, 1) contentar-se em fixar e repetir o conteúdo da existência imediata de povos e civilizações, contribuindo para a retificação dos conteúdos culturais que presidem as diferentes formas de pensar e agir das sociedades humanas ou 2) exacerbar, no plano do consumerismo globalizante de nossa civilização ocidental, a fome canibal do Exótico, do Diferente, do Estranho, encarregado de reduzi-los a um princípio de Unidade. (o que remete aqui, nos termos de um processo filogenético, pensar o próprio nascimento das relações entre o Psicanálise e a Antropologia). 